\title{
Pengembangan Game Edukasi Berbasis Flash Sebagai Sarana Belajar Siswa PAUD
}

\author{
Fathirma'ruf \\ Program Studi Pendidikan Teknologi Informasi, STKIP Yapis Dompu \\ E-mail:fathir.ntb@gmail.com
}

Article History: Received: 2021-05-12 || Revised: 2021-07-17 || Published: 2021-08-15

Sejarah Artikel : Diterima: 2021-05-12 || Direvisi: 2021-07-17 || Dipublikasi: 2021-08-15

\begin{abstract}
Educational games are one type of media used to provide instruction, increase user knowledge through a unique and interesting medium. This type is usually intended for children, so the color game is really needed here, not the level of difficulty that is important. This research development model uses ADDIE. The ADDIE model is one of the systematic learning design models. Data collection techniques in this study were observation, interviews, documentation, questionnaire (questionnaire). The research instrument used in this study was an interview guide, questionnaire sheets including validation sheets (media experts), validation sheets (material experts) and test questions. Based on the results of the study, the validity analysis of the media was $78 \%$ validation of material experts $72 \%$ validation of the student response questionnaire instrument was $85 \%$. Analysis of the results of the data on the ability to improve learning outcomes was carried out on 4 respondents, namely pre test analysis (initial ability) 60 and post test analysis (final ability) $80 \%$ so that the product developed was feasible to use. In general, it can be concluded that the development of flash-based educational games to improve the learning outcomes of PAUD students is feasible.
\end{abstract}

Keywords: Educational Games, Adobe Flash CS6, Learning Outcomes

\begin{abstract}
Abstrak
Pengembangan adalah kegiatan ilmu pengetahuan dan teknologi yang bertujuan memanfaatkan kaidah dan teori ilmu pengetahuan yang telah terbukti kebenarannyauntuk meningkatkan fungsi, manfaat, dan aplikasi ilmu pengetahuan dan teknologi yang telah ada atau menghasilkan teknologi baru. Game Edukasi adalah salah satu jenis media yang digunakan untuk memberikan pengajaran, menambah pengetahuan penggunanya melalui suatu media unik dan menarik. Jenis ini biasanya ditujukan untuk anak- anak, maka permainan warna sangat diperlukan disini bukan tingkat kesulitan yang dipentingkan. Model pengembangan penelitian ini menggunakan ADDIE. Model ADDIE merupakan salah satu model desain pembelajaran sistematik. Teknik pengumpulan data dalam penelitian ini adalah observasi, wawancara, kusieoner (angket). Instumen penelitian yang digunakan dalam penelitian ini adalah pedoman wawancara, lembar angket, lembar angket meliputi lembar validasi (ahli media), lembar validasi (ahli materi) dan. Berdasarkan hasil penelitian, validitas media $78 \%$ validitasi ahli materi $94 \%$. Secara umum dapat disimpulkan bahwa pengembangan Game Edukasi berbasis flash sebagai sarana berlajar siswa PAUD layak digunakan.
\end{abstract}

Kata kunci: Pengembangan, Game Edukasi, Adobe Flash CS6, Siswa PAUD

\section{PENDAHULUAN}

Belajar menurut Syah (2008: 89) adalah "kegiatan yang berproses dan merupakan unsur yang sangat fundamental dalam setiap penyelenggaraan jenis dan jenjang pendidikan". Ini berarti bahwa tercapai tidaknya tujuan pendidikan bergantung pada proses belajar yang dialami anak, baik di lingkungan keluarga, sekolah, maupun masyarakat. Dalam arti yang sederhana, belajar merupakan proses perubahan tingkah laku. Perubahan tingkah laku ini disebabkan oleh pengalaman yang diperoleh ketika dan setelah mempelajari sesuatu, Sedangkan Hinztman dalam Syah (2008: 90) belajar adalah "perubahan yang terjadi dalam diri organisme (manusia atau hewan) disebabkan oleh pengalaman yang mempengaruhi tingkah laku organisme tersebut". Jadi menurutnya, organisme dikatakan belajar apabila terjadi perubahan yang ditimbulkan oleh pengalaman 
tersebut. Pakar psikologi belajar tersebut juga menambahkan bahwa, "pengalaman hidup seharihari dalam bentuk apapun sangat memungkinkan untuk diartikan sebagai belajar". Pemikiran inilah yang melahirkan bahwa sesungguhnya belajar itu sepanjang hayat.

Perkembangan kualitas belajar merupakan dampak dari perkembangan iptek yang sangat pesat. Perkembangan iptek mengharuskan penyesuaian dan peningkatan proses secara berlanjut dan terus menerus atau jangka panjang. Hal ini diikuti dengan perlunya mengadakan pembaharuan konsep-konsep dan strategi pembelajaran untuk meningkatkan kualitas hasil pembelajaran itu sendiri, UU Sisdiknas (2003) pasal 1 ayat 14 menyatakan bahwa pendidikan anak usia dini adalah suatu upaya pembinaan yang ditujukan kepada anak sejak lahir sampai dengan usia enam tahun, Sangatlah rugi jika sebuah keluarga atau masyarakat mengabaikan program yang sudah ditetapkan oleh pemerintah yaitu Pendidikan Anak Usia Dini (PAUD) yang sebenarnya sudah tertera UU di atas yang menegaskan bahwa Pendidikan Anak Usia Dini adalah suatu upaya pembinaan yang ditujukan kepada anak sejak lahir sampai dengan usia enam tahun yang dilakukan melalui pemberian ransangan pendidikan untuk membantu pertumbuhan dan perkembangan jasmani dan rohani agar anak memiliki kesiapan dalam memasuki pendidikan lebih lanjut (Sisdiknas, 2004: 4), Perkembangan teknologi yang pesat sekarang ini berpengaruh terhadap proses pembelajaran di sekolah dan berpengaruh juga pada materi pembelajaran serta cara penyampaian materi dalam proses kegiatan belajar mengajar. Pada tahap pendidikan anak usia dini, siswa akan cenderung lebih tertarik dengan permainan yang mudah dimainkan dan di dalamnya terdapat angka, huruf, warna-warna cerah serta gambar animasi yang menarik perhatian. Dan dalam tahap ini siswa akan lebih mudah mengingat suatu bentuk atau tulisan yang memiliki ciri warna menarik dan bentuk yang komunikatif dan menyenangkan. Sedangkan saat ini kebanyakan pembelajaran di sekolah masih menggunakan metode pembelajaran konvesional.

Berdasarkan hasil observasi awal yang dilakukan oleh peneliti pada tanggal 23 November 2020, melalui pengamatan dan wawancara yang dilakukan dan diperoleh informasi bahwa proses pembelajaran yang dilakukan oleh guru PAUD masih cenderung pasif hal ini ditunjukan oleh terbatasnya alat peraga yang digunakan dalam proses belajar mengajar, selain itu cara mengajar guru yang konvesional cenderung membuat siswa tidak aktif dalam menerima pembelajaran dan hal ini berdampak pada hasil belajar siswa sebanyak 30\% yang tidak memenuhi kriteria ketuntasan minimum $>75 \%$ yang telah ditetapkan, untuk itu peneliti berinisiatif mengembangkan perangkat pembelajaran Game Edukasi yang unggul dalam beberapa aspek jika dibandingkan dengan metode pembelajaran konvensional demi meningkatan hasil belajar siswa, dengan media perangkat pembelajaran game Edukasi ini akan membuat siswa lebih mudah mengingat materi yang disampaikan oleh guru karena disajikan dalam tampilan yang menyenangkan. Dalam game edukasi ini, siswa akan barmain dan belajar, dengan berbagai macam materi dan permainan yang di sajikan di dalam game

\section{METODE PENELITIAN}

Saat ini model pengembangan yang dapat digunakan dalam penelitian dan pengembangan (research and Development) cukup beragam. Dari berbagai macam model penelitian, peneliti mengambil salah satu model pengembangan yaitu model ADDIE (Analyz, Design, Development, implementation, Evaluation). Model ADDIE merupakan salah satu model desain pembelajaran sistematik. Romiszowski (1996) mengemukakan bahwa pada tingkat desain materi pembelajaran dan pengembangan, sistematik sebagai aspek prosedural prosedural pendekatan sistem telah diwujudkan dalam banyak praktik metodologi untuk desain dan pengembangan teks, materi audiovisual dan materi pembelajaran berbasis komputer. Model ADDIE terdiri atas lima langkah, yaitu: a) analisis (Analyz), b) perancangan, (design), c) pengembangan (development), d) implementasi, (implementation) dan e) evaluasi (evaluation).

\section{HASIL DAN PEMBAHASAN}

Penyajian data hasil uji coba adalah suatu penyajian data setelah dilakukannya validasi terhadap oleh dosen STKIP Yapis Dompu yang terdiri dari dua orang (validator) Hasil Uji coba produk bertujuan untuk mengetahui layak atau tidak multimedia pembelajaran. Adapun hasil validasi tersebut antara lain sebagai berikut: 
a) Hasil Validasi Oleh Ahli Media

Lembar validasi bertujuan untuk mengetahui kelayakan hasil dari suatu produk yang dikembangkan. Dari tabel dibawah ini dapat dilihat hasil validasi oleh ahli media. Yang merupakan salah satu dosen STKIP Yapis Dompu, yang mengerti tentang media dan apa saja yang perlu dicantumkan pada Game Edukasi. Produk yang telah dinilai pada tanggal $21 \mathrm{Mei}$ 2021 dengan menggunakan lembar validasi ahli media.

Tabel 1. Hasil Validasi Ahli Media

\begin{tabular}{|c|c|c|c|c|c|c|c|c|c|c|c|c|c|c|}
\hline \multirow{2}{*}{ No } & \multicolumn{12}{|c|}{ Distribusi Jawaban Validator } & \multirow{2}{*}{$\begin{array}{c}\text { Skor } \\
\text { Perolehan }\end{array}$} & \multirow{2}{*}{$\begin{array}{l}\text { Skor } \\
\text { Maks }\end{array}$} \\
\hline & 1 & 2 & 3 & 4 & 5 & 6 & 7 & 8 & 9 & 10 & 11 & 12 & & \\
\hline 1 & 5 & 4 & 4 & 4 & 4 & 5 & 3 & 4 & 4 & 3 & 4 & 4 & 39 & 50 \\
\hline \multicolumn{13}{|c|}{ Jumlah } & 39 & 50 \\
\hline & & & & & & & & Pre & ent & se $\mathrm{K}$ & lay & & \multicolumn{2}{|c|}{$78 \%$} \\
\hline
\end{tabular}

Berdasarkan validasi yang dilakukan ahli media didapat nilai dengan presentase $78 \%$ dapat kita lihat pada tabel diatas bahwa media yang tercantum pada Game Edukasi sangat valid untuk digunakan.

b) Hasil Validasi oleh Ahli Materi

Dari hasil validasi oleh Ahli materi yang juga dilakukan oleh salah satu dari Dosen STKIP Yapis Dompu. pada tanggal 1 Juni 2021 dengan menggunakan lembar validasi ahli media seperti yang diuraikan dalam table hasil validasi berikut ini:

Tabel 2. Hasil Validasi Ahli Materi

\begin{tabular}{|c|c|c|c|c|c|c|c|c|c|c|c|c|c|c|}
\hline \multirow{2}{*}{ No } & \multicolumn{12}{|c|}{ Distribusi Jawaban Validator } & \multirow{2}{*}{$\begin{array}{c}\text { Skor } \\
\text { Perolehan }\end{array}$} & \multirow{2}{*}{$\begin{array}{l}\text { Skor } \\
\text { Maks }\end{array}$} \\
\hline & 1 & 2 & 3 & 4 & 5 & 6 & 7 & 8 & 9 & 10 & 11 & 12 & & \\
\hline 1 & 4 & 5 & 3 & 4 & 4 & 4 & 4 & 3 & 4 & 5 & 4 & 3 & 47 & 50 \\
\hline \multicolumn{13}{|c|}{ Jumlah } & 47 & 50 \\
\hline & & & & & & & & Pre & IIU & se $\mathrm{K}$ & lay & & \multicolumn{2}{|c|}{$94 \%$} \\
\hline
\end{tabular}

Dari data hasil validasi oleh ahli materi diatas dapat dilihat pada tabel diatas didapat nilai dengan presentase 94\%. Jadi dapat disimpulkan bahwa materi yang terdapat dalam Game Edukasi layak untuk digunakan

c) Analisis Data Hasil Penelitian

Analisis Hasil Validasi Pengembangan Game Edukasi Berbasis Flash sebagai sarana belajar Siswa PAUD antara lain: 1) Data hasil validasi oleh ahli media tentang Pengembangan Game Edukasi berbasis Flash sebagai sarana belajar Siswa PAUD. Berdasarkan validasi yang dilakukan ahli media didapat nilai hasil validasi dengan persentase $78 \%$, jadi dapat disimpulkan bahwa media yang dihasilkan layak untuk digunakan, sedangkan 2) Data hasil validasi yang didapat dari ahli materi didapat nilai dengan persentase 94\%. Berdasarkan validasi dari ahli materi sangat layak untuk digunakan, Berdasarkan Hasil uji validasi yang dilukan didapat nilai dari uji ahli validasi media sebesar $78 \%$ dan hasil uji validasi dari ahli media didapat nilai sebesar $94 \%$ Jadi dapat di ambil kesimpulan bahwa pengembangan game edukasi berbasis flash sebagai sarana belajar siswa PAUD layak untuk digunakan.

d) Revisi Produk yang dikembangkan

Setelah melakukan validasi dengan ahli media dan ahli materi, pengembangan Game edukasi sebgai sarana belajar siswa direvisi sesuai dengan saran dan masukan yang di berikan. Perbaikan dilakukan agar layak untuk digunakan sebagai bahan ajar, Berikut adalah saran dan masukan produk yang akan direvisi, Gambar dibawah ini adalah gambar halaman kuis sebelum dan setelah dilakukan perbaikan sesuai dengan arahan dari validator, yang dimana pada scan ini dilakukan revisi karena animasi yang terdapat didalamnya tidak bergerak sehingga perlu dilakukan perbaikan dan perubahan sedikit perubahan warna. 


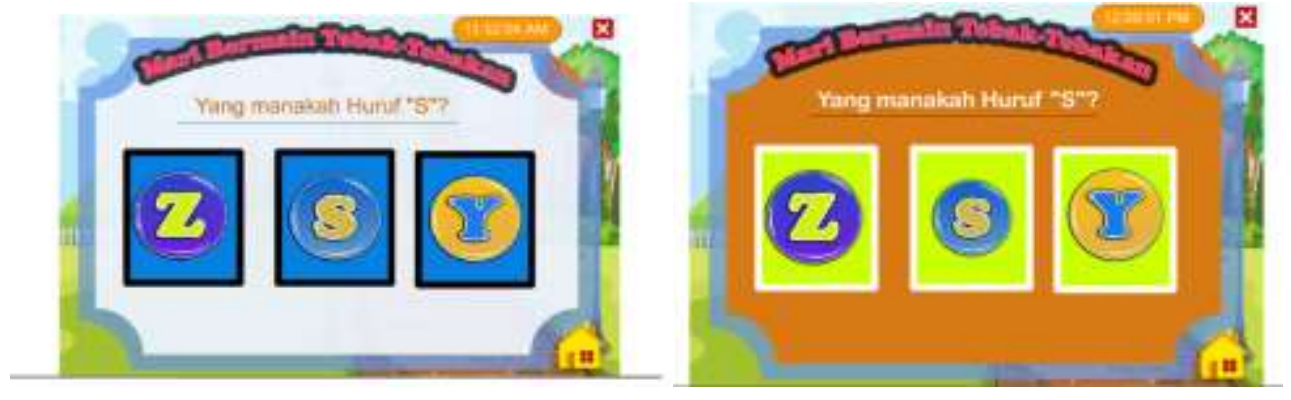

Gambar 1. halaman kuis sebelum dan setelah dilakukan perbaikan

\section{SIMPULAN DAN SARAN}

\section{A. Simpulan}

Berdasarkan hasil validasi dan penyajian data pada pengembangan Game Edukasi bahwa hasil validasi perangkat pembelajaran yang terdiri dari lembar ahli media, lembar ahli materi, Penilaian lembar validasi ahli media mendapatkan jumlah nilai 78 sedangkan hasil validasi oleh ahli materi mendapatkan jumlah nilai 94\%. Dengan demikian hasil validasi Game edukasi sebagai sarana belajar siswa Paud masuk kategori 'Layak' dan dapat digunakan sebagai sarana belajar, Dengan demikian dapat ditarik kesimpulan bahwa pengembangan Game Edukasi berbasis Flash sebagai sarana belajar siswa PAUD layak digunakan sesaui dengan hasil validasi.

\section{B. Saran}

Berdasarkan hasil pembahasan dan kesimpulan, dapat diberikan saran sebagai berikut:

1. Diharapakan kepada Pendidik dan Peserta didik dapat menggunakan produk dengan baik sebagai sarana belajar siswa.

2. Game edukasi Berbasis Flash yang telah dikembangkan ini dapat diteruskan dan dikembangkan oleh peneliti berikutnya dengan keberlanjutan pada uji kelayakan dan kepraktisan perangkat yang telah dikembangkan.

3. Diharapakan kepada peneliti selanjutnya agar menambahkan animasi dan fitur-fitur yang lebih menarik lagi sehingga produk yang dikembangkan mendapatkan hasil yang maksimal.

\section{DAFTAR RUJUKAN}

Angela, W., \& Gani, A. (2016). Rancang Bangun Game Edukasi Berbasis Web Dan Android Menggunakan Adobe Flash Cs5 Dan Action Script 3.0. IJIS-Indonesian Journal On Information System, 1(2).

Anggara (Zulfadli Fahrul Rozi), 2010, “ULTIMATE GAME DESAIN Building RPG Games Using Adobe Flash Action Script", ANDI, Yogyakarta.

Anggraeni, Mutia Dian, Sigit Santoso, and Binti Muchsini. (2016). "Peningkatan Prestasi Belajar Siswa Melalui Penerapan Game Edukasi Akuntansi." Jurnal “Tata Arta” UNS 2.2

Azhar Arsyad. (2002 :26). “Media Pembelajaran. Jakarta”: PT. RajaGrafindo Persada

Bakhri, Syamsul. (2019) "Animasi Interaktif Pembelajaran Huruf dan Angka Menggunakan Model ADDIE." INTENSIF: Jurnal Ilmiah Penelitian dan Penerapan Teknologi Sistem Informasi 3.2: 130-144.

Darti, yulia. 2020. pengembangan media berbasis adobe flash untuk meningkatkan perkembangan kognitif anak usia 5-6 tahun. diss. UIN Raden Intan Lampung.

Dewi, Ghea Putri Fatma. (2012). "Pengembangan game edukasi pengenalan nama hewan dalam bahasa inggris sebagai media pembelajaran siswa sd berbasis macromedia flash." Skripsi, 
Program Studi Pendidikan Teknik Informatika Fakultas Teknik Universitas Negeri Yogyakarta, Yogyakarta.

Eka Yulianti, \& Taufik. (2020). Studi Perbandingan Eksistensi Alam Pada Novel Tanah Baru Tanah Air Kedua Karya Nh. Dini Dan Sri Rinjani Karya Eva Nourma (Tinjauan Ekologi Sastra). Ainara Journal (Jurnal Penelitian Dan PKM Bidang Ilmu Pendidikan), 1(2), 44-55. https://doi.org/10.1234567/ainarajournal.v1i2.13

Fatchan, Muhamad. (2018): "Perancangan Aplikasi Media Pembelajaran Ilmu Pengetahuan Alam berbasis Adobe Flash Professional CS6." Jurnal SIGMA 8.1 43-51.

Fathirma'ruf, \& Muhammad Akbar. (2018). Perancangan Sistem Seleksi Penerimaan Calon Mahasiswa Baru Berbasis Website. JIIP - Jurnal Ilmiah Ilmu Pendidikan, 1(3), 102-106. Retrieved from http://iiip.stkipyapisdompu.ac.id/iiip/index.php/IIIP/article/view/28

Fatih Holis Ahnaf, Farida Rochmawati, Safira Hamdala, \& Muzemil. (2021). Pengembangan Media Pembelajaran Berbasis Animasi pada Materi Fonologi untuk Mahasiswa menggunakan PowerPoint. Ainara Journal (Jurnal Penelitian Dan PKM Bidang Ilmu Pendidikan), 2(2), 5965. https://doi.org/10.1234567/ainarajournal.v2i2.26

Haryasena, Jarot Anton. 2013. "Perancangan Game Edukasi Untuk Anak Usia Dini (4-6 Tahun) Berbasis Android" Diss. Universitas Muhammadiyah Surakarta.

Ija Srirahmawati. (2021). Peran Guru Sebagai Fasilitator dalam Mengasah Penalaran Matematika Siswa SDN 29 Dompu Tahun Pembelajaran 2020/2021. Ainara Journal (Jurnal Penelitian Dan PKM Bidang Ilmu Pendidikan),2(2), 114-123. Retrieved from http://journal.ainarapress.org/index.php/ainj/article/view

Purwaningsih, Esty. (2018) "Mengenal warna, angka, huruf dan bentuk pada anak usia dini melalui animasi interaktif." JITK (Jurnal Ilmu Pengetahuan Dan Teknologi Komputer) 3.2 : 203-210.

Putranto, Adhi. (2013) "Pengembangan Game Edukasi Klasifikasi Hewan Menggunakan Adobe Flash Professional CS5 Sebagai Media Pembelajaran Biologi Kelas VII Di SMP N 15 Yogyakarta." Pendidikan Teknik Informatika.

Rozi, Fahrur, and Khalimatul Khomsatun. (2019) "Rancang Bangun Game Edukasi Pengenalan Warna Untuk Pendidikan Anak Usia Dini Menggunakan Adobe Flash Berbasis Android." JIPI (Jurnal Ilmiah Penelitian dan Pembelajaran Informatika) 4.1 12-18.

Sari, Nurmala Indah. (2016) "Pengembangan Media Pembelajaran Biologi Melalui Pemanfaatan Barang Bekas di Madarasah Aliyah Negeri 3 Biringkanaya Makassar. Diss. Universitas Islam Negeri Alauddin Makassar. 